Jurnal Ilmiah Rekayasa dan Manajemen Sistem Informasi, Vol. 5, No. 2, Agustus 2019, Hal. 208-217

e-ISSN 2502-8995 p-ISSN 2460-8181

\title{
KLASIFIKASI PERMASALAHAN AGENSTOK MENGGUNAKAN ALGORITMA NAIVE BAYES CLASSIFIER PADA PT. HPAI- PEKANBARU
}

\author{
${ }^{1}$ Zarnelly, ${ }^{2}$ Maya Andiany \\ Email: ${ }^{1}$ zarnelly71@gmail.com, ${ }^{2}$ maya.andiany@ students.uin-suska.ac.id \\ ${ }^{1,2}$ Program Studi Sistem Informasi, Fakultas Sains dan Teknologi, \\ Universitas Islam Negeri Sultan Syarif Kasim Riau
}

\begin{abstract}
ABSTRAK
Kecendrungan seseorang untuk mengakses informasi khususnya permasalahan agenstok melalui dunia maya pun menjadi semakin tinggi. Informasi merupakan hal yang sangat penting dalam kehidupan masyarakat. Salah satu sumber infomasi adalah media sosial. Klasifikasi ini ditekankan untuk data permasalahan agenstok. Pada umumnya permasalahan yang disampaikan terdiri dari beberapa kategori seperti permasalahan mengenai kesehatan, konsultasi produk dan marketing. Namun dalam membagi permasalahan kedalan kategori-kategori tersebut untuk saat ini masih dilakukan secara manual.hal ini sangat merepotkan apabila permasalahan yang ingin di unggah berjumlah banyak. Oleh karena itu, perlu adanya sistem yang bisa mengklasifikasikan permasalahan secara otomatis. Text mining merupakan metode klasifikasi yang merupakan variasi dari data mining yang berusaha menemukan pola menarik dari sekumpulan data tekstual yang berjumlah banyak. Sedangkan algoritma naive bayes classsifier merupakan logartitma pendukung utuk melakukan klasifikasi. Kategori memiliki jumlah data permasalahan yang sama dan terdiri dari 400 data permasalahan; 360 data permasalahan digunakan untuk proses training dan 40 data permasalahan digunakan untuk proses testing. Pada penelitian ini metode yang digunakan yaitu waterfall dan pengujian perfomance measure, uji black box, dan uji sistem oleh pengguna. Adapun pengujian perfomance measure memperoleh nilai akurasi $97,5 \%$, precision $97,6 \%$, recall $97,5 \%$ dan $f$-measure $97,4 \%$. Dari hasil-hasil tersebut dapat disimpulkan bahwa sistem yang menerapkan algoritma naive bayes classifier dapat digunakan untuk mengklasifikasikan permasalahan agenstok berbasis web, dengan menggunakan bahasa pemrograman PHP dan Database Management System (DBMS) menunjukkan bahwa klasifikasi permasalahan agenstok bisa terklasifikasi secara otomatis.
\end{abstract}

Kata Kunci: agenstok, akurasi, klasifikasi, nä̈ve bayes, text mining

\section{A. PENDAHULUAN}

Teknologi informasi merupakan elemen vital dalam proses informasi yang dilakukan pada sebuah instansi atau perusahaan. Pentingnya peranan elemen tersebut telah mendorong terciptanya berbagai macam upaya untuk dapat memenuhi kebutuhan data dan informasi dengan melakukan import data yang cepat, efektif dan akurat. Salah satu contoh bidang yang membutuhkan teknologi informasi dalam kemajuan instansinya adalah bidang perdagangan dan jasa. Begitu pula PT. Herba Penawar Alwahida Indonesia, yang memiliki agen tersebar ke seluruh Indonesia yang memiliki peran penting sebagai konsultan bisnis dan sebagai agen terdepan dalam memasarkan produk yang mereka miliki. Dalam prakteknya, setiap orang bisa menjadi agen yang menjual produk.

Umumnya setiap agenstok memiliki beberapa masalah umum hingga spesifik sehingga untuk kasus yang sama harus diselesaikan secara berulang-ulang. Manajer akan memeriksa riwayat permasalahan yang ada di setiap masing-masing agenstok. Manajer merasa kesulitan untuk mengkategorikan permasalahan dari sistem konsultasi yang telah dibangun sebelumnya. Pada umumnya kategori permasalahan yang dikategorikan oleh konsultan terdiri dari beberapa kategori seperti mengenai kesehatan, konsultasi produk dan marketing. Namun dalam membagi permasalahan untuk kategori tersebut saat ini masih dilakukan secara manual. Salah satu sistem yang menangani konsultasi ini, awalnya menyediakan fitur kepada agenstok untuk mengisi keluhan-keluhan yang sedang dihadapinya.

Klasifikasi merupakan salah satu metode dalam data mining yang bertujuan untuk mendefenisikan kelas dari sebuah objek yang belum diketahui kelasnya. Pada klasifikasi terlebih dahulu akan dilakukan proses training dan testing. Klasifikasi dokumen bertujuan untuk mengelompokkan dokumen yang tidak terstruktur ke 
dalam kelompok yang menggambarkan isi dari dokumen [1].

Dalam penelitian ini menggunakan metode berbasis statistik yaitu naive bayes yang memiliki kelebihan hanya memerlukan komputasi matematika yang tidak terlalu komplek sehingga sangat efesien dalam aplikasi praktis. Metode ini juga terbukti handal dengan tingkat akurasi cukup tinggi [2].

Pengklasifikasian permasalahan secara otomatis bisa dikategorikan sebagai text mining. Proses text mining dibagi menjadi tiga tahap, yaitu proses awal terhadap teks(text preprocessing), transformasi teks kedalam bentuk antara (text transformation/feature generation), dan penemuan pola (pattern discovery) [3].

\section{B. LANDASAN TEORI}

\section{B.1. Klasifikasi}

Klasifikasi merupakan suatu pekerjaan menilai objek data untuk memasukkannya kedalam kelas dari sejumlah kelas yang tersedia. Dalam klasifikasi ada dua pekerjaan utama yang dilakukan, yaitu pertama, pembangunan model sebagai prototype untuk disimpan sebagai memori dan kedua, penggunaan model tersebut untuk melakukan pengenalan, klasifikasi, prediksi pada suatu objek data lain agar diketahui kelas mana objek data tersebut dalam model yang sudah disimpan

Pada klasifikasi terdapat variabel target yang berupa nila kategorikal (nominal). Contoh dari klasifikasi adalah pendapatan masyarakat digolongkan kedalam tiga kelompok, yaitu pendapatan tinggi, pendapatan sedang, dan pendapatan rendah. Algoritma yang biasa digunakan adalah naive bayes [4].

\section{B.2. Text Mining}

Text mining adalah suatu proses knowledge-based dimana pengguna berinteraksi dan bekerja dengan sekumpulan dokumen dengan menggunakan beberapa alat analisis.

Prosedur utama dalam metode ini terkait dengan menemukan kata-kata yang dapat mewakili isi dari dokumen untuk selanjutnya dilakukan analisis keterhubungan antar dokumen dengan menggunakan metode statistik tertentu seperti analisis kelompok, klasifikasi, dan asosiasi. Langkah-langkah yang dilakukan text mining [5].

\section{Text Preprocessing}

Text Preprocesing merupakan tahap tokenisasi yang merupakan proses pemecahan teks menjadi bentuk kata atau disebut sebagai token.

\section{Text Transformation/Feature Generation}

Pada tahap ini hasil yang diperoleh dari tahap text preprocessing akan melalui proses transformasi, dilakukan dengan mengurangi jumlah kata-kata yang ada dengan perhitungan kata-kata yang dianggap tidak penting (stopword)

\section{Stemming Bahasa Indonesia}

Dalam bahasa Indonesia, afiks/imbuhan terdiri dari sufiks(akhiran), infiks (sisipan), dan prefiks (awalan).

\section{Pattern Discovery}

Tahap penemuan polapPattern Discovery adalah tahap terpenting dari seluruh proses text mining. Tahap ini berusaha menemukan pola atau pengetahuan dari keseluruhan teks.

\section{B.3. Term Frequency-Inverse Document Frequency (TF-IDF)}

Term Frequency-Inverse Document Frequency adalah statistik numerik yang mengungkapkan tingkat kepentingan kata sebuah dokumen dalam suatu koleksi. Term Frequency-Inverse Document Frequency sering digunakan sebagai faktor pembobotan dalam information retrieval dan text mining. Nilai TF-IDF meningkat secara proporsional berdasarkan berapa banyak kemunculan kata dokumen (term frequency), tetapi dinetralkan oleh frekuensi kata dalam ccorpus (inverse document frequency).

Metode ini menggabungkan dua konsep untuk perhitungan bobot, yaitu frekuensi kemunculan kata didalam sebuah dokumen yang diberikan menunjukkan seberapa penting kata itu didalam dokumen tersebut. Rumus untuk TF-IDF [6]

\section{B.4. Confusion Matrix}

Confusion matrix adalah sebuah tabel yang menyatakan jumlah data uji yang salah diklasifikasikan. Berdasarkan jumlah keluaran kelasnya, sistem klasifikasi dibagi menjadi empat jenis yaitu, klasifikasi binary, multi-class, malti-label dan hierarchial. Pada klasifikasi binary, data masukan dikelompokkan kedalam salah satu dari dua kelas [7].

Tabel 1 Confusion Matrix untuk multiclass

\begin{tabular}{|c|c|c|c|c|}
\hline \multicolumn{2}{|c|}{} & \multicolumn{3}{|c|}{ Kelas Prediksi } \\
\cline { 3 - 5 } \multicolumn{2}{|c|}{} & 1 & 2 & 3 \\
\hline Kelas & 1 & TP & FN & TN \\
\hline
\end{tabular}


Jurnal Ilmiah Rekayasa dan Manajemen Sistem Informasi, Vol. 5, No. 2, Agustus 2019, Hal. 208-217 e-ISSN 2502-8995 p-ISSN 2460-8181

\begin{tabular}{|l|l|l|l|l|}
\hline \multirow{2}{*}{ Sebenarnya } & 2 & FP & TN & FP \\
\cline { 2 - 5 } & 3 & TP & FP & TN \\
\hline
\end{tabular}

Keterangan untuk tabel confusion matrix

True Possitive $\left(\mathrm{TP}_{\mathrm{i}}\right)$, yaitu jumlah data positif yang terklasifikasi dengan benar oleh sistem untuk kelas ke-i.

True Negative $\left(\mathrm{TN}_{\mathrm{i}}\right)$, yaitu jumlah data negatif yang terklasifikasi dengan benar oleh sistem untuk kelas ke-i.

False Negative $\left(\mathrm{FN}_{\mathrm{i}}\right)$, yaitu jumlah data negatif namun terklasifikasi salah oleh sistem untuk kelas kei.

False Positive $\left(\mathrm{FP}_{\mathrm{i}}\right)$, yaitu jumlah data positif namun terklasifikasi salah oleh sistem untuk kelas ke-i.

\section{B.5. Nä̈ve Bayes Classifier (NBC)}

NBC adalah metode klasifikasi yang berdasarkan probabilitas dan Teorema Bayesian dengan asumsi bahwa setiap variable $\mathrm{X}$ bersifat bebas (independence). Dengan kata lain, NBC mengasumsikan bahwa keberadaan sebuah atribut (variable) tidak ada kaitannya dengan keberadaan atribut (variable) yang lain. Perhitungan perbandingan antara term pada testing dengan setiap kelas yang ada dengan menggunakan persamaan berikut [7]:

Keterangan:

$$
P\left(v_{j}\right)=\frac{n_{c}+m p}{n+m}
$$

$$
\begin{array}{ll}
\mathrm{n} & =\text { jumlah term pada data latih dimana } \mathrm{v}=\mathrm{v}_{\mathrm{j}} \\
\mathrm{nc} & =\text { jumlah term dimana } \mathrm{v}=\mathrm{v}_{\mathrm{j}} \text { dan } \mathrm{a}=\mathrm{a}_{\mathrm{j}} \\
\mathrm{p} & =\text { probabilitas setiap kelas dalam data latih } \\
\mathrm{m} & =\text { jumlah term pada data uji }
\end{array}
$$

Adapun untuk menentukan klasifikasi pada data uji digunakan persamaan:

$$
V_{M A P}=\operatorname{argmax}_{j \in V} P\left(v_{j}\right) \prod P\left(a_{i} \vee v_{j}\right)
$$

\section{B.6. Phyton}

Python adalah bahasa pemrograman yang fleksibel dan sederhana yang didefinisikan dalam dokumen-dokumennya sebagai berikut [8]:

1. Python adalah bahasa pemrograman tujuan umum yang sangat tingkat tinggi, dinamis, berorientasi objek, yang umum digunakan

2. bisa digunakan dalam aplikasi yang luas.

3. Bahasa ini dapat mendukung berbagai gaya pemrograman termasuk struktural dan

berorientasi objek. Gaya lain juga bisa digunakan.

4. Python sangat fleksibel, karena kemampuannya untuk menggunakan komponen modular yang dirancang dalam bahasa pemrograman lainnya. Sebagai contoh, Anda dapat menulis sebuah program di $\mathrm{C}++$ dan mengimpornya ke python sebagai modul.

\section{B.7. Basis data (Database)}

Basis data dapat diartikan sebagai suatu pengorganisasian sekumpulan data yang saling terkait sehingga memudahkan aktifitas untuk memperoleh informasi. Basis data dimaksudkan untuk mengerti problem pada sistem yang memakai pendekatan berbasis berkas. Secara lebih lengkap, tujuan basis data adalah sebagai berikut:

1. Kecepatan dan kemudahan (speed)

2. Efesiensi ruang penyimpanan (space)

3. Keakuratan (accuracy)

4. Ketersediaan (availability)

5. Kelengkapan (completness)

6. Keamanan (security)

7. Kebersamaan pemakai (sharability)

\section{B.8. Software Pendukung}

Dalam merancang sistem berbasis web dibutuhkan beberapa aplikasi pendukung seperti:

1. MySQL

MySQL adalah sebuah open source sistem manajemen database SQL yang dikembangkan, didistribusikan oleh Oracle Corporation. Keistimewaan dari MySQL adalah dapat berjalan stabil di berbagai sistem operasi [9].

\section{PHP}

PHP adalah bahasa pemrograman script side yang didesain untuk mengembangkan web yang dapat ditanamkan ke dalam bahasa. Tujuan utama dari bahasa ini adalah agar pengembang web mampu menulis halaman web secara dinamis [10].

\section{UML (Unified Modelling Language)}

Notasi UML dibuat sebagai kolaborasi dari Grady Booch, DR. James Rumbough dan lainnya. UML menyediakan beberapa diagram yang menunjukkan berbagai aspek dalam sistem seperti usecase diagram, activity diagram, sequence diagram, dan class diagram. Tujuan perancangan UML adalah[11]:

1. Menyediakan basis formal untuk pemahaman bahasa pemodelan 
2. Mendorong pertumbuhan pasar kakas berorientasi objek.

\section{METODOLOGI DAN DATA}

\section{C.1. Metodologi}

Metodologi yang diterapkan dalam melakukan penelitian ditunjukan pada Gambar 1.

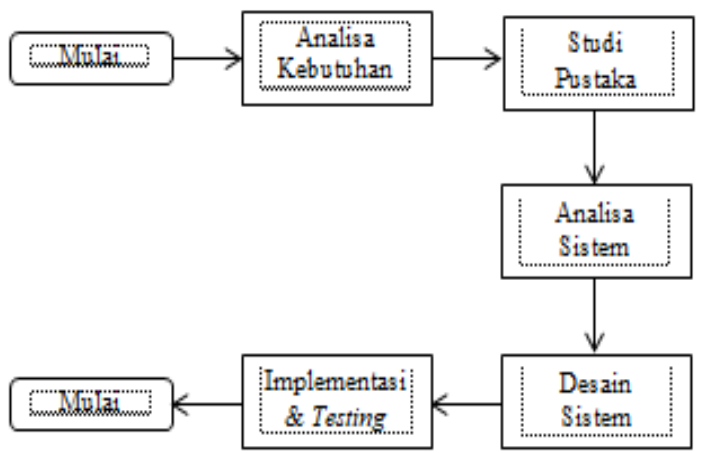

Gambar 1. Metodologi Penelitian

\section{C.2. Kebutuhan Data}

Sebelum melakukan proses klasfikasi, hal pertama yang dilakukan pada penelitian ini adalah mengumpulkan data permasalahan agenstok yang nantinya akan digunakan sebagai dataset. Data dikumpulkan secara manual melalui gruop whatsapp. Data permasalahan yang dikumpulkan berjumlah 1.200 data, waktu pengumpulan data permasalahan dengan rentang waktu bulan Januari sampai dengan Desember 2018 dan disimpan dengan format *xlsx. Selanjutnya menentukan kategori permasalahan yang akan dijadikan sebagai kelas pada proses klasifikasi menggunakan metode yang dibahas dalam penelitian ini. Adapun kategori dan ciri-ciri permasalahan adalah sebagai berikut:

1. Kesehatan

Beberapa permasalahan kesehatan ditandai dengan informasi yang ada dalam keluhan agenstok seperti berikut:
a. Cara untuk menggemukkan badan
b. Meningkatkan kecerdasan otak anak
c. Membantu pertumbuhan tinggi badan
d. Mengurangi kadar gula
e. Menjaga kesehatan mata

2. Konsultasi Produk
Beberapa contoh keluhan konsultasi produk ditandai dengan informasi yang ada dalam keluhan agenstok seperti berikut:

a. Madu yang bisa menguatkan daya hapal anak

b. Cara mengkonsumsi produk herbal

c. Khasiat produk herbal

d. Kegunaan promol2

e. Takaran pemberian obat herbal berdasarkan umur

\section{Marketing}

Beberapa contoh keluhan marketing ditandai dengan informasi yang ada dalam keluhan agenstok seperti berikut:

a. Syarat menjadi stokis

b. Daerah yang ada stokis dan pusat agensi

c. Cara menghitung bonus

d. Syarat pendaftaran menjadi agen

e. Cara menggunakan sistem AVO

\section{C.3. Studi Pustaka}

Tahapan ini merupakan tahapan dimana dilakukan informasi untuk lebih mengetahui tentang masalah dan teori-teori yang mendukung mengenai teori yang digunakan dalam penelitian ini. Studi pustaka dilakukan dengan membaca buku-buku, referensi, jurnal, dan penelitian sebelumnya yang membahas tentang klasifikasi, text mining, dan algoritma naive bayes classifier.

\section{C.4. Analisa Sistem} berikut:

Analisa sistem yang dilakukan adalah sebagai

1. Pre-processing

Tahapan yang dilakukan adalah:

a. Case folding, bertjuan untuk mengubah semua huruf kapital menjadi huruf kecil

b. Tokenizing, semua permasalahan agenstok yang telah dilakukan case folding akan dipisah menjadi token.

c. Stemming, konversi ke kata dasar.

d. Filtering, menyaring kata-kata yang tidak penting pada permasalahan agentok.

e. Indexing, membuat indeks kata dari permasalahan agenstok yang telah melalui proses tahapan sebelumnya.

f. Pembobotan kata, memberikan bobot pada kata yang telah indeks dengan menggunakan teknik pembobotan TF-IDF.

2. Analisa Sistem yang diusulkan 
Jurnal Ilmiah Rekayasa dan Manajemen Sistem Informasi, Vol. 5, No. 2, Agustus 2019, Hal. 208-217 e-ISSN 2502-8995 p-ISSN 2460-8181

Penggunaan text mining untuk klasifikasi permasalahan menggunakan metode naive bayes classifier merupakan sebuah sistem yang dapat membantu mengklasifikasikan permasalahan menjadi lebih baik. Sistem ini dapat melakukan proses klasifikasi kategori masalah berdasarkan sistem informasi konsultasi agenstok berbasisi web yang telah dibangun pada penelitian sebelumnya. Kemudian sistem akan melakukan klasifikasi kategori permasalahan secara otomatis, agar data tersebut selanjutnya dapat disimpan kedalam database.

\section{C.5. Desain Sistem}

Dalam tahap ini ada empat perancangan yang akan dibuat, yaitu perancangan struktur menu dibuat menggunakan tools Ms. Visio 2007, Perancangan interface sistem yang akan dibuat menggunakan tools Mockup Balsamiq 3.5.7. Nota grafis yang menggunakan Unified Modelling Language (UML) meliputi Usecase diagram, Activity diagram, Sequence diagram, dan class diagram.

\section{C.6. Implementasi}

Implementasi merupakan tahap yang dilakukan setelah melakukan analisa dan perancangan. Data yang telah dianalisa sistem yang dirancang akan di implementasikan ke dalam bentuk tampilan dan koding. Pada penelitian ini, implementasi dilakukan dengan menggunakan laptop dengan spesifikasi perangkat keras yang dimiliki processsor Intel(R) Core(TM) i3 CPU M330@2.13 GHz, Kapasitas memori 4 GB, dan Hardisk 500 GB.

\section{C.7.Testing}

Setelah dilakukan implementasi, maka dilakukan pengujian terhadap sistem yang telah dibuat untuk mengetahui tingkat keberhasilan sistem yang telah dibangun menggunakan parameter pengujian yang ditentukan. Pada pengujian ini parameter yang digunakan adalah:

\section{Blackbox Testing}

Blackbox testing berkaitan dengan pengujianpegujian yang dilakukan pada antarmuka perangkat lunak. Pengujian ini juga disebut pengujian fungsional karena pengujihanya melakukan pengujian pada perangkat lunak yang berkaitan dengan fungsionalitas dan bukan pada implementasi perangkat lunak. [14]

\section{UAT (User Acceptance Test)}

Pengujian yang dilakukan oleh pengguna dari sistem untuk memastikan fungsi-fungsi yang ada pada sistem tersebut telah berjalan dengan baik dan sesuai dengan kebutuhan pengguna. Hasil dari UAT adalah dokumen yang menunjukkan bukti pengujian dan diambil kesimpulan apakah software yang diuji dapat diterima [15]

\section{Pengujian Akurasi, Precision, recall dan $F$ -} measure.

Perhitungan nilai akurasi didapat setelah mengetahui jumlah data uji yang benar diklasifikasikan. Perhitungan precision akan mengukur tingkat kepastian atau jumlah data testing yang diklasifikasikan dengan benar oleh model klasifikasi yang dibangun. Recall merupakan kebalikan dari precision. F-measure didapat dari perhitungan pembagian hasil dari perkalian precison dan recall, kemudian dikalikan dua [7].

\section{ANALISIS DAN PEMBAHASAN \\ D.1. Pengumpulan Data}

Tahap pengumpulan data menjadi tahap berikutnya pada penelitian ini yaitu tahap setelah dilakukan tahap perencanaan. Pengumpulan data didapaptkan dari Whatsapp. Total data yang dikumpulkan sebanyak 1.200 permasalahan data agenstok.

Tabel 2. Data Permasalahan Agenstok

\begin{tabular}{|c|c|c|}
\hline No & Keluhan & Kelas \\
\hline 1 & $\begin{array}{l}\text { Kalau untuk menggemukkan badan apa } \\
\text { ya? }\end{array}$ & Kesehatan \\
\hline 2 & $\begin{array}{l}\text { Saya kemarin sudah pernah daftar tapi } \\
\text { belum ada dapat kartu anggota sampai } \\
\text { sekarang, bagaimana? }\end{array}$ & Marketing \\
\hline 3 & $\begin{array}{l}\text { Aturan minum sari kurma untuk anak } \\
\text { umur } 3 \text { tahun, bagaimana? }\end{array}$ & $\begin{array}{l}\text { Konsultasi } \\
\text { Produk }\end{array}$ \\
\hline 4 & $\begin{array}{l}\text { Assalamualaikum, untuk } \\
\text { meningkatkan kecerdasan nutrisi otak } \\
\text { anak apa }\end{array}$ & Kesehatan \\
\hline 5 & $\begin{array}{l}\text { Apa saja syarat untuk membangun } \\
\text { pusat agensi }\end{array}$ & $\begin{array}{c}\text { Konsultasi } \\
\text { Produk }\end{array}$ \\
\hline$\ldots$. & $\ldots$ & $\ldots$ \\
\hline 1200 & $\begin{array}{l}\text { Assalamualaikum, stokis daerah } \\
\text { harapan raya dimananya? }\end{array}$ & Marketing \\
\hline
\end{tabular}

\section{D.2. Arsitektur Sistem Klasifikasi Permasalahan}

Berikut arsitektur sistem klasifikasi permasalahan agenstok terlihat pada Gambar 2. 


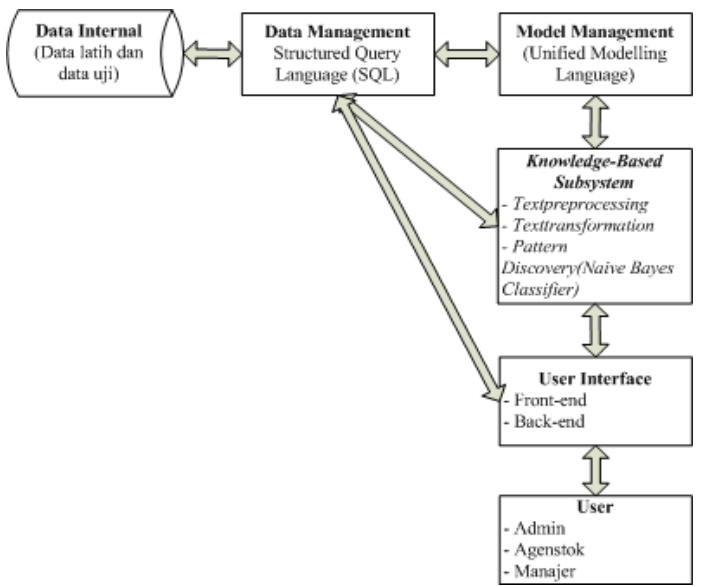

Gambar 2. Arsitektur Sistem Klasifikasi Permasalahan

\section{D.3. Gambaran Umum Sistem Klasifikasi}

Sistem klasifikasi permasalahan agenstok ini merupakan suatu sistem yang mendukung pengelolaan data berbentuk teks secara otomatis dari hasil pengolahan data, informasi dan perancangan sistem. Dalam klasifikasi permasalahan ini, menggunakan metode Naive Bayes Classifier (NBC) dan proses yang paling penting dalam sistem ini yaitu penambangan sebuah teks pada suatu dokumen, sehingga dapat memberikan hasil yang sesuai dengan tujuan yang akan dicapai. Berikut gambaran umum sistem yang akan dibuat pada Gambar 3.

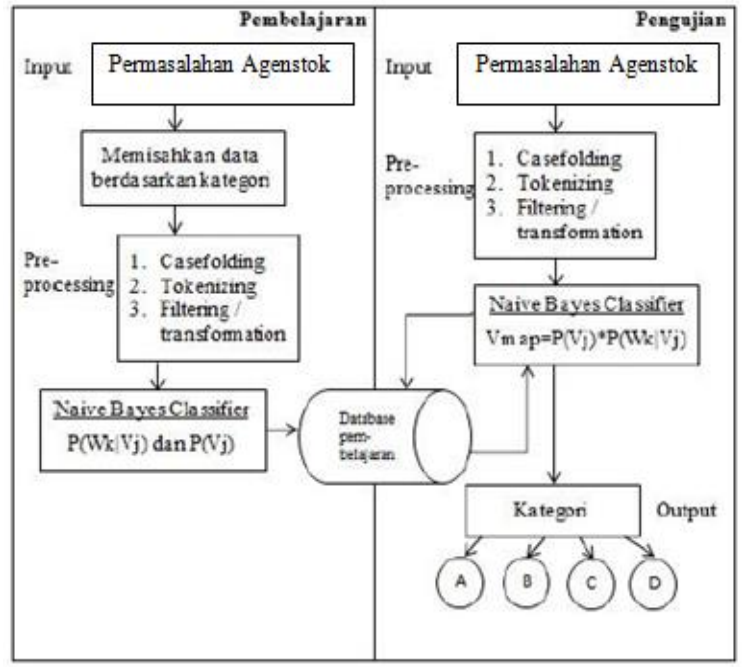

Gambar 3 Gambaran Umum Sistem Klasifikasi
Dapat dilihat pada Gambar 3 sistem yang akan dibangun terdapat dua proses yang berbeda yaitu proses pembelajaran(training) dan proses pengujian(testing).

1. Proses training, data permaslahan yang sudah dimasukkan akan dipisahkan berdasarkan kategori yang telah ditentukan. Kemudian data yang sudah dipisahkan masuk ketahap preprocessing (casefolding, tokenizing, dan filtering), setelah itu dihitung nilai probabibiltas kata dan probabilitas kategori pada setiap data yang dijadikan data training, kemudian disimpan ke dalam database training yang berisi kata-kata penting pada setiap kategori.

2. Sedangkan pada proses testing yang menjadi data masukkan yaitu data permaslaahan baru yang belum diketahui kategorinya. Pada tahap preprocessing yang dilakukan pada proses preprocesing didalam proses training, yang membedakannya yaitu pada saat perhitungan probabilitas setiap kata. Setelah melakukan tahap preprocessing, maka dokumen baru tersebut akan melalui proses persamaan kata. Kata-kata yang ada di data baru dengan katakata yang ada di proses training. Sehingga menghasilkan probabilitas pada setiap kategori yang ada.

\section{D.4. Data Training dan Data Testing}

Data latih (data training) dan data uji (data testing) diambil dari dataset awal dengan jumlah 1.200 permasalahan agenstok setelah melalui beberapa tahapan. Data tersebut dibagi untuk dilakukan pengujian menggunakan algoritma Nä̈ve Bayes Classifier. Data dibagi menjadi data training dan data testing dengan perbandingan 90:10, dimana masing-masing kategori memliki data latih yang berjumlah 360 data permasalahan dan memiliki data uji di setiap kategori yang berjumlah 40 data permasalahan.

\section{D.5. Text Preprocessing}

Tahap pre-processing atau praproses data merupakan proses untuk mempersiapkan data mentah sebelum dilakukan proses lain. Pada umumnya, praproses data dilakukan dengan cara mengeliminasi data yang tidak sesuai atau mengubah data menjadi bentuk yang lebih mudah diproses oleh sistem.

Pada tahapan filtering, yaitu pembuangan kata-kata tidak penting dari hasil token. Selain itu juga dilakukan penghapusan tanda baca dan 
Jurnal Ilmiah Rekayasa dan Manajemen Sistem Informasi, Vol. 5, No. 2, Agustus 2019, Hal. 208-217 e-ISSN 2502-8995 p-ISSN 2460-8181

stopword. Stopword diproses pada sebuah kalimat jika mengandung kata-kata yang sering keluar dan di anggap tidak penting seperti waktu, penghubung, dan lain sebagainya. Untuk itu perlu dilakukan penghapusan. Untuk melakukan proses penghapusan kata ini diperlukan sebuah data atau daftar kata yang diinginkan untuk dihapus. Adapun daftar kata yang digunakan adalah stoplist tala (Tala, 2003) dengan jumlah 758 stopwords [16]. Berikut adalah stopword yang digunakan yang dapat dilihat pada Tabel 3 .

Tabel 3. Daftar Stoplist (Tala, 2003)

\begin{tabular}{|c|l|c|l|c|l|}
\hline No & Stopword & & Stopword & & Stopword \\
\hline 1 & Ada & 11 & Akhiri & 21 & Antaranya \\
\hline 2 & Adalah & 12 & Akhirnya & 22 & Apa \\
\hline 3 & Adanya & 13 & Aku & 23 & Apaan \\
\hline 4 & Adapun & 14 & Akulah & 24 & Apabila \\
\hline 5 & Agak & 15 & Amat & 25 & Apakah \\
\hline 6 & Agaknya & 16 & Amatlah & 26 & Apalagi \\
\hline 7 & Agar & 17 & Anda & 27 & Apatah \\
\hline 8 & Akan & 18 & Andalah & 28 & Artinya \\
\hline 9 & Akankah & 19 & Antar & $\ldots$ & $\ldots$ \\
\hline 10 & Akhir & 20 & Antara & 758 & Yang \\
\hline
\end{tabular}

Pada tahapan stemming, yaitu pengubahan kata berimbuhan menjadi kata dasar dan pada tahapan ini menggunakan modul sastrawi pada python. Sedangkan pada tahapan tokenizing, setiap kata akan dipisahkan berdasarkan spasi yang ditemukan. Hasil text preprocessing dapat dilihat pada Tabel 4.

Tabel 4. Hasil text preprocessing

\begin{tabular}{|c|c|c|}
\hline No & Keluhan & Kelas \\
\hline 1 & untuk gemuk badan ya & Kesehatan \\
\hline 2 & $\begin{array}{c}\text { kemarin pernah daftar belum dapat kartu } \\
\text { anggota sekarang }\end{array}$ & Marketing \\
\hline 3 & atur minum sari kurma anak bagaimana & $\begin{array}{c}\text { Konsultasi } \\
\text { Produk }\end{array}$ \\
\hline 4 & assalamualaikum tingkat cerdas nutrisi & Kesehatan \\
otak & pusat agensi & Marketing \\
\hline 5 & testimoni promol12 tanam jagung & $\begin{array}{c}\text { Konsultasi } \\
\text { Produk }\end{array}$ \\
\hline 6 & batuk masuk angin herbalnya & Kesehatan \\
\hline 7 & assalamualaikum daerah kandang stok & Marketing \\
\hline 8 & obat lebih sepesifik sakit satu obat & $\begin{array}{c}\text { Konsultasi } \\
\text { Produk }\end{array}$ \\
\hline 9 & kapur sendi herbalnya & Kesehatan \\
\hline 10 & .... & Marketing \\
\hline$\ldots$ & ada stok harap raya & \\
\hline 1.200 & &
\end{tabular}

\section{D.6. Term Frequency-Inverse Document Frequency (TF-IDF)}

Setiap keluhan dilakukan pembobotan dengan menggunakan persamaan. TF-IDF dihitung dengan ketentuan mengeliminasi term atau kata dengan frekuensi pada dokumen kurang dari 3\% (Reza, 2017). Pada perhtiungan TF-IDF menggunakan bahasa pemrograman python.

Dengan melalui proses text mining yaitu proses preprocessing (casefolding, tokenizing, dan filtering), maka didapat jumah banyak kata sebanyak 5.215 dan jumlah frekuensi dari masing-masing kategori, jumlah frekuensi kategori kesehatan $=1.858$, jumlah frekuensi kategori konsultasi produk $=2.030$, jumlah frekuensi kategori marketing $=1.327$.

\section{D.7. TF-IDF Pada Data Training}

Pembobotan TF-IDF pada $90 \%$ data training didapat sebanyak 5.215 kata. Kemudian hitung nilai probabilitas dengan menggunakan rumus:

$\mathbf{P}\left(\mathbf{W}_{\mathbf{k}} \mid \mathbf{V}_{\mathbf{j}}\right)=(\mathbf{n k}+\mathbf{1}) /($ Jumlah Frekuensi+Jumlah Kata)

Dimana:

$\mathbf{P}\left(\mathbf{W}_{\mathbf{k}} \mid \mathbf{V}_{\mathbf{j}}\right)=$ Probabilitas bobot kata sesuai kategori nk = Nilai kemunculan frekuensi kata (untuk mencari nilai kemunculan frekuensi didapat dari tabel keyword).

Prediksi : Apa obat untuk menjaga kesehatan mata

Setelah melewati hasil akhir yaitu stemming, kemudian dihitung nilai probabilitasnya kategori kesehatan, konsultasi prosuk dan marketing menggunakan rumus 4.14

Hasil probabilitas kategori kesehatan adalah:

$\mathrm{P}($ obat $\mid$ Kesehatan $)=(121+1) /(1.858+5.215)=$ 0,0173

$\mathrm{P}($ jaga $\mid$ Kesehatan $)=(3+1) /(1.858+5.215)=0,0005$

$\mathrm{P}($ sehat $\mid$ Kesehatan $)=(2+1) /(1.858+5.215)=0,0004$

$\mathrm{P}($ mata $\mid$ Kesehatan $)=(11+1) /(1.858+5.215)=$ 0,0016

Hasil probabilitas kategori konsultasi produk adalah:

$\mathrm{P}($ obat $\mid$ Konsultasi Produk $)=(17+1) /(2.030+5.215)$ $=0,0024$

$\mathrm{P}($ jaga $\mid$ Konsultasi Produk $)=(2+1) /(2.030+5.215)=$ 0,0004

$\mathrm{P}($ sehat $\mid$ Konsultasi Produk $)=(3+1) /(2.030+5.215)$ $=0,0005$

$\mathrm{P}($ mata $\mid$ Konsultasi Produk $)=(0+1) /(2.030+5.215)$ $=0,0001$

Hasil probabilitas kategori marketing adalah:

$\mathrm{P}($ obat $\mid$ Marketing $)=(0+1) /(1.327+5.215)=0,0001$

$\mathrm{P}($ jagal Marketing $)=(0+1) /(1.327+5.215)=0,0001$

$\mathrm{P}($ sehat $\mid$ Marketing $)=(0+1) /(1.327+5.215)=0,0001$ 
$\mathrm{P}($ mata $\mid$ Marketing $)=(0+1) /(1 \cdot 327+5.215)=0,0001$

Setelah mendapatkan nilai probabilitas kata pada setiap kategori, kemudian hitung probabilitas kategori dengan menggunakan rumus :

$\mathbf{P}(\mathbf{V j})=$ Jml Dokumen setiap Kategori / Total Dokumen

Diketahui : Jumlah Dokumen Kesehatan $=360$ : Jumlah Dokumen Konsultasi Produk $=360$

: Jumlah Dokumen Marketing $=360$

Jadi, probabilitas dari dokumen adalah :

$\mathrm{P}($ Kesehatan $)=360 / 1200=0.3$

$\mathrm{P}($ Konsultasi Produk $)=360 / 1200=0.3$

$\mathrm{P}($ Marketing $)=360 / 1200=0.3$

Sedangkan, pembobotan pada $10 \%$ data uji dapat dilihat pada Tabel 6 dengan term yang berbeda. Pembobotan ini digunakan untuk percobaan akurasi pada $10 \%$ data uji. Berikut ini perhitungan nilai probabilitas pada setiap kategori. Nilai yang dimasukkan berdasarkan data latih pada Tabel 5

1. Kategori Kesehatan

$$
\begin{aligned}
& \mathrm{P}(\text { obat| Kesehatan }) \quad=0,0173 \\
& \mathrm{P}(\text { jaga| Kesehatan }) \quad=0,0005 \\
& \mathrm{P}(\text { sehat| Kesehatan }) \quad=0,0004 \\
& \mathrm{P}(\text { mata| Kesehatan }) \quad=0,0016 \\
& \text { Jadi } \mathrm{P}(\mid \text { Kesehatan }) \quad=0,0173 * 0,0005 * 0,0004 \\
& * 0,0016
\end{aligned}
$$

Kesehatan)

$$
\begin{array}{r}
=0,3 * 0,00000000000554 \\
=0.00000000000116
\end{array}
$$

Tabel 5. Probabilitas Data Uji

\begin{tabular}{|c|c|c|c|}
\hline No. & Kesehatan & $\begin{array}{c}\text { Konsultasi } \\
\text { Produk }\end{array}$ & Marketing \\
\hline 1 & $5.34340^{-10}$ & $2.29329^{-19}$ & $4.38195^{-27}$ \\
\hline 2 & 0.001516 & $8.289394^{-06}$ & $1.15003^{-27}$ \\
\hline 3 & $1.133337^{-05}$ & $4.554612^{-08}$ & $2.50007^{-38}$ \\
\hline 4 & $1.167052^{-06}$ & $3.2793209^{-15}$ & $3.00008^{-36}$ \\
\hline$\ldots$ & $\ldots$ & $\ldots$ & $\ldots$ \\
\hline 120 & $8.333333^{-39}$ & $1.4166667^{-37}$ & $\begin{array}{c}1.119698^{-} \\
05\end{array}$ \\
\hline
\end{tabular}

\section{D.8. Deskripsi Fungsional Sistem}

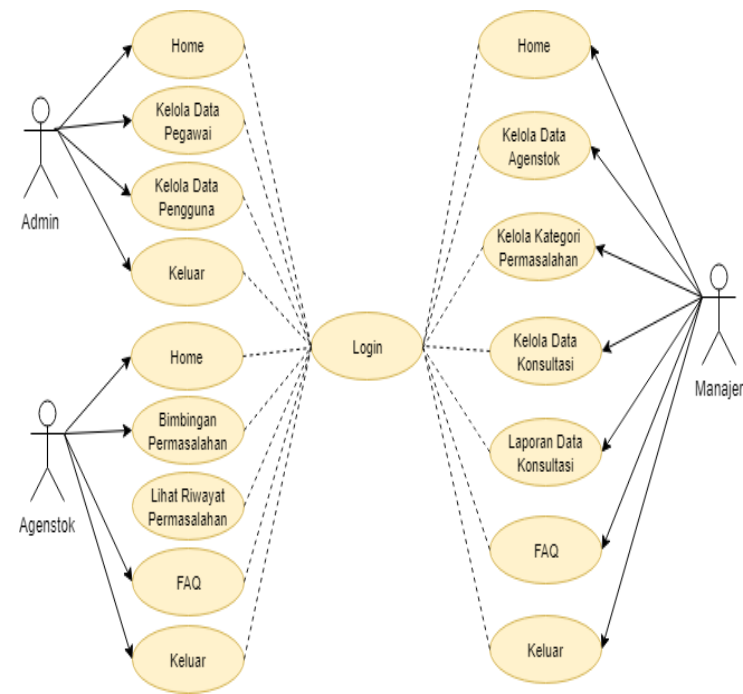

Gambar 4. Usecase Diagram

\section{D.9. Implementasi dan Pengujian}

\section{D.9.1. Implementasi}

Tahap ini sistem siap dioperasikan oleh user. Pengguna sistem terdapat 3 aktor, yaitu admin, manajer, dan agenstok. Sistem klasifikasi pada aktor manajer terlihat pada Gambar 5.

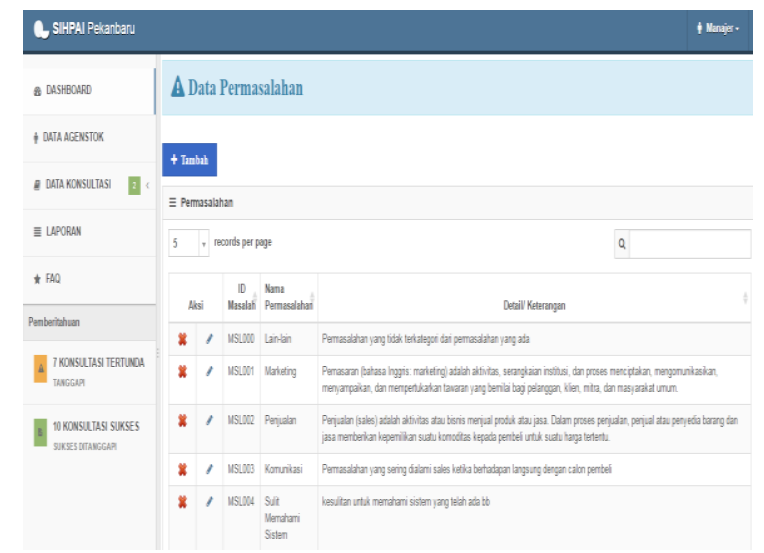

Gambar 5. Kategori masalah

Tampilan form Klasifikasi Otomatis pada aktor manajer terlihat pada Gambar 6.

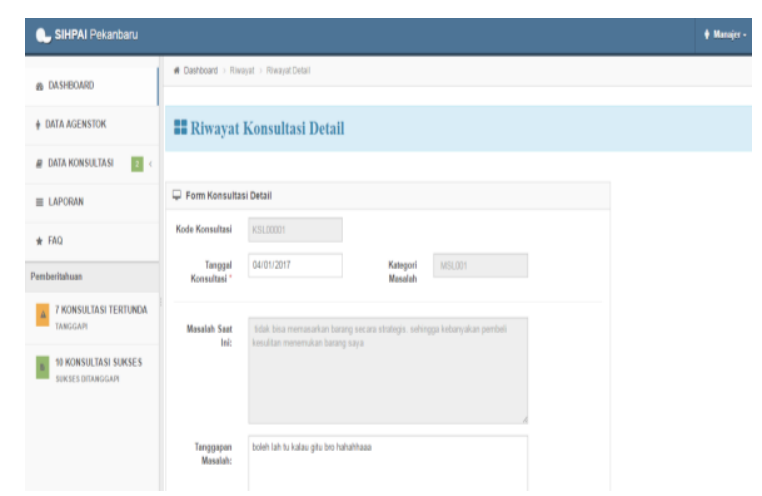


Jurnal Ilmiah Rekayasa dan Manajemen Sistem Informasi, Vol. 5, No. 2, Agustus 2019, Hal. 208-217 e-ISSN 2502-8995 p-ISSN 2460-8181

\begin{tabular}{|l|c|c|c|c|c|}
\hline & Kesehatan & $\begin{array}{c}\text { Konsultasi } \\
\text { Produk }\end{array}$ & \multicolumn{2}{c|}{ Marketing } \\
\hline Kesehatan & 40 & \multicolumn{2}{c|}{0} & 0 & 40 \\
\hline KonsulProduk & \multicolumn{2}{|c|}{3} & 37 & 0 & 40 \\
\hline Marketing & \multicolumn{2}{|c|}{0} & 0 & 40 & 40 \\
\hline & 43 & 37 & 40 \\
\hline
\end{tabular}

Gambar 6. Tampilan Form Klasifikasi Otomatis

\section{D.9.2. Pengujian}

Pengujian dilakukan untuk melihat hasil implementasi, apakah sistem berjalan sesuai tujuan atau masih terdapat kesalahan-kesalahan. Metode pengujian hasil klasifikasi dilakukan untuk mengetahui tingkat keakurasian sistem dengan menggunakan confusion matrix (akurasi) precission, recall dan $f$-measure, sedangkan metode pengujian sistem menggunakan Blackbox Testing dan User Accaptance Test (UAT). Bentuk pengujian ini untuk memastikan fungsi-fungsi yang ada pada sistem tersebut telah berjalan dengan baik dan sesuai dengan kebutuhan pengguna.

\section{Pengujian Hasil Klasifikasi}

Klasifikasi permasalahan pada PT. Herba Penawar Alwahida Indonesia melalui 2 tahapan utama, yaitu tahap pelatihan (training) yang masingmasing data dibagi dengan perbandingan $90 \%$ data pelatihan dan $30 \%$ data pengujian seperti pada Tabel 6 . Kemudian setelah proses klasifikasi selesai hasil klasifikasi diandingan dengan 4 pengujian yaitu akurasi, precission, recall dan f-measure untuk mengetahui data yang relavan sesuai kategori atau tidak.

Tabel 6. Jumlah Data Training dan Data Testing

\begin{tabular}{|c|l|c|c|}
\hline No & Kategori & $\begin{array}{c}\text { Data } \\
\text { Pelatihan }\end{array}$ & $\begin{array}{c}\text { Data } \\
\text { Pengujian }\end{array}$ \\
\hline 1 & Kesehatan & 360 & 40 \\
\hline 2 & Konsultasi Produk & 360 & 40 \\
\hline 3 & Marketing & 360 & 40 \\
\hline \multicolumn{2}{|c|}{ Jumlah } & 1080 & 120 \\
\hline Total & \multicolumn{2}{|c|}{1200} \\
\hline
\end{tabular}

\section{Confusion Matrix}

Confusion matrix adalah tools yang digunakan untuk evaluasi model klasifikasi untuk memperkirakan objek yang benar atau salah. Sebuah matrix dari prediksi yang akan dibandingkan dengan kelas asli dari inputan atau dengan kata lain berisi informasi nilai aktual dan prediksi pada klasifikasi.

Tabel 7. Klasifikasi dan Prediksi

\begin{tabular}{l|r} 
Klasifikasi & Prediksi Kelas \\
\hline
\end{tabular}

Adapun hasil pengujian klasifikasi tiga kategori, terlihat pada Tabel 8.

Tabel 8. Tabel Pengujian Klasifikasi

\begin{tabular}{|l|c|c|c|l|}
\hline Evaluasi & Kesehatan & $\begin{array}{c}\text { Konsul } \\
\text { Produk }\end{array}$ & Marketing & $\begin{array}{l}\text { Rata- } \\
\text { rata }\end{array}$ \\
\hline Akurasi & 100 & 92,5 & 100 & 97,5 \\
\hline Precision & 93,02 & 100 & 100 & 97,6 \\
\hline Recall & 100 & 92,5 & 100 & 97,5 \\
\hline F-measure & 96,3 & 96,1 & 100 & 97,4 \\
\hline
\end{tabular}

Pada tabel akurasi diatas menampilkan hasil pengujian klasifikasi yang telah dilakukan, terdapat 4 pengujian dengan demikian dapat disimpulkan bahwa:

1. Nilai tertinggi terdapat pada pengujian precision dengan nilai $97,6 \%$

2. Pengujian hasil klasifikasi pada akurasi dengan nilai $97,5 \%$

3. Pengujian hasil klasifikasi pada recall dengan nilai $97,5 \%$

4. Pengujian hasil klasifikasi pada f-measure dengan nilai $97,4 \%$

\section{E. KESIMPULAN}

Adapun setelah didapatkan hasil penelitian ini, kesimpulan yang didapatkan yaitu:

1. Sistem klasifikasi dibuat sesuai dengan algoritma yang digunakan yaitu algoritma naive bayes classifier. Dimana hasil pengujian klasikasi permasalahan yang dilakukan oleh sistem sudah sesuai dengan hasil klasifikasi secara manual.

2. Sistem mengklasifikasi permasalahan agenstok berdasarkan query konsultasi dengan menggunakan metode naive bayes classifier ini berhasil mengklasifikasikan permasalahan agenstok dalam kategori kesehatan, konsutasi produk dan marketing dengan tingkat rata-rata akurasi mencapai $97,5 \%$.

3. Sistem menentukan klasifikasi permasalahan agenstok sesuai dengan hasil klasifikasi yang dilakukan secara manual dan sesuai dengan pengelompokkan permasalahan yang diinginkan oleh user

\section{REFERENS}


[1] Februariyanti, H., \& Zuliarso, E. (2012). Klasifikasi Dokumen Berita Teks Bahasa Indonesia Menggunakan Ontologi. Jurnal Teknologi Informasi. Dinamik, 17(1).

[2] Mahmudy, W, F., dan Widodo, A. W. (2015).. Klasifikasi artikel berita secara otomatis menggunakan metode naive bayes classifier yang dimodifikasi. TEKNO, 21(1).

[3] Sanjaya, S., dan Absar, E.A. (2015). Pengelompokkan dokumen menggunakan winnowing fingerprint dengan metode k-Nearest neighbour. Jurnal Hail Penelitian Ilmu Komputer dan Teknologi Informasi, 1(2), 50-56.

[4] Prasetyo, E. (2012). Data mining konsep dan aplikasi menggunakan matlab". Yogyakarta: Andi.

[5] Indriani, A. (2014). Klasifikasi data forum dengan menggunakan metode naive bayes classifier. Jurnal Fakultas Hukum UII.

[6] Nurjannah, M., Hamdani, \& Astuti, I, F. (2016). Penerapan algoritma term frequency -inverse document frequency (tf-idf) untuk text mining". Informatika Mulawarman: Jurnal Ilmiah Ilmu Komputer, 8(3), 110-113.
[7] Purwanti, E. (2012). Klasifikasi dokumen temu kembali informasi dengan k-nearest neighbour". Record and Library Journal, 1(2).

[8] Nosrati, M. (2011). Phyton: An Appropriate Language For Real World Programming. World Applied Programming, 1(2), 110-117.

[9] Bartholomew, D. (2012). Mariadb vd. Mysq1. Dostopano, 7(10), 2014.

[10] Ullman, L. (2011). Php and mysql for dynamic web sites: Visual quickpro guide. Peachpit Press.

[11] Sholiq, P .S. I. B. O. (2006). dengan uml. Yogyakarta: Graha Ilmu.

[12] Ratnawati. "Pengembangan Aplikasi Profil Sekolah Berbasis Augmented Reality Sebagai Media Informasi Profil Sekolah di SMA Negeri 1 Wonogiri". [Skripsi] Universitas Gunadarma. Yogyakarta. 2016

[13] Zarnelly, dan Adelia, D. (2015). Rancang bangun media pelayanan umum desk info info berbasisi web (Studi kasus: Pengadilan Tinggi Agama Pekanbaru). Jurnal Informatika Rekayasa dan Manajemen Sistem Informasi, 1(2), 55-59.

[16] Tala, F. Z.A. (2003). A Study of Stemming Efects on Information Retrieval in Bahasa Indonesia, Institute for Logic, Language and Computation Van Amsterdam, The Netherlands. 